\title{
Population-based analysis of esophageal large cell neuroendocrine carcinoma between 2004 and 2015
}

\author{
Guangda Yuan ${ }^{1 \#}$, Cheng Zhan ${ }^{2 \#}$, Donglin Zhu ${ }^{1}$, Hongya Xie ${ }^{1}$, Tengteng Wei ${ }^{1}$, Tao Lu ${ }^{2}$, Yong Yang ${ }^{1}$, \\ Yimeng Zhu' ${ }^{1}$, Qun Wang ${ }^{2}$ \\ ${ }^{1}$ Department of Thoracic Surgery, The Affiliated Suzhou Hospital of Nanjing Medical University, Suzhou 215001, China; ${ }^{2}$ Department of Thoracic \\ Surgery, Zhongshan Hospital of Fudan University, Shanghai 200032, China \\ Contributions: (I) Conception and design: G Yuan, C Zhan, Y Yang, Y Zhu, Q Wang; (II) Administrative support: Y Yang, Q Wang; (III) Provision \\ of study materials or patients: D Zhu, H Xie, T Wei, T Lu; (IV) Collection and assembly of data: G Yuan, C Zhan, Y Yang; (V) Data analysis and \\ interpretation: G Yuan, C Zhan, Y Yang; (VI) Manuscript writing: All authors; (VII) Final approval of manuscript: All authors. \\ \#These authors contributed equally to this work. \\ Correspondence to: Yong Yang. Department of Thoracic Surgery, The Affiliated Suzhou Hospital of Nanjing Medical University, Suzhou 215001, \\ China. Email: yangy_suzhou@126.com.
}

\begin{abstract}
Background: Esophageal large cell neuroendocrine carcinoma (ELCNC) seems a rarely gastrointestinal malignancy. By far, its clinicopathological characteristics and prognosis have not been deeply studied.

Methods: The data of patients having ELCNC was extracted from the Surveillance, Epidemiology, and End Results (SEER) database, then assessed and compared with information from patients with esophageal small cell neuroendocrine carcinoma (ESCNC) or esophageal squamous cell carcinoma (ESCC). We used univariate and multivariate analyses to accurately detect independent prognostic factors.

Results: The data of 36 patients for ELCNC were obtained between 2004 and 2015. Compared with patients with ESCNC and ESCC, the mean survival time of ECLNC patients was worse than those with ESCC, while similar to ESCNC. Thus, ELCNC had significantly different clinicopathological characteristics compared to ESCNC and ESCC. Univariate and multivariate analyses revealed that age $(\mathrm{P}=0.001)$ and $\mathrm{M}$ stage $(\mathrm{P}=0.004)$ were independent prognostic factors.

Conclusions: ELCNC is a rare subtype of esophageal neuroendocrine carcinoma. The clinicopathological features differ from those of other esophageal carcinomas. Prognosis may be closely related to age and $\mathrm{M}$ stage.
\end{abstract}

Keywords: Esophageal large cell neuroendocrine carcinoma (ELCNC); SEER database; prognosis; overall survival (OS)

Submitted Mar 02, 2019. Accepted for publication Oct 10, 2019.

doi: $10.21037 /$ jtd.2019.11.34

View this article at: http://dx.doi.org/10.21037/jtd.2019.11.34

\section{Introduction}

Esophageal carcinoma generally has a high mortality rate and poor prognosis, with a dramatic increase in incidence of approximately 572,000 new cases and 509,000 deaths detected per year worldwide for 36 cancer types, in 185 countries. Approximately $70 \%$ of the cases occur in males, and a nearly 2 - to 3 -fold difference in mortality rates is noted among the sexes (1). In addition to small cell carcinoma of esophageal cancers, esophageal large cell neuroendocrine carcinoma (ELCNC) is accepted as a rarely malignant, esophageal neuroendocrine tumor $(2,3)$, which accounts for $3.80 \%$ to less than $30 \%$ of primary esophageal neuroendocrine carcinomas $(4,5)$.

ELCNC has unique clinicopathological features. According to the currently used classification, the pathological manifestations of esophageal large cell carcinoma are mainly large cancer cells, more mononuclear 
or multinucleated giant cells, and thus have higher mitotic cell numbers $(6,7)$. In this study, we utilized the SEER (Surveillance, Epidemiology, and End Results) database to compare the clinicopathological characteristics between ELCNC, esophageal small cell neuroendocrine carcinoma (ESCNC), and esophageal squamous cell carcinoma (ESCC) to better predict the prognoses of patients by analyzing the related risk factors of ELCNC.

\section{Methods}

\section{Data extraction}

The comprehensive data of ELCNC patients diagnosed from 2004 to 2015 were extracted from the SEER database (http://seer.cancer.gov/) using SEER*Stat software version 8.3.5 (https://seer.cancer.gov/seerstat/). The study recruited patients according to the third edition (ICD-O-3) histology code $8013 / 3$, as determined by the International Classification of Diseases for Oncology. Each selected patient had histopathologically proven malignant ELCNC. Patients with non-primary tumors, less detailed personal features, and incomplete follow-up data were excluded.

\section{Variables}

Race, age, sex, insurance type, marital status, tumor size, number of malignant tumors, grade, the American Joint Committee on Cancer (AJCC) stage of the primary cancer, therapeutic methods used, vital status, year of diagnosis, and survival data of selected patients were included in the SEER database. The TNM staging system was confirmed according to the AJCC seventh edition criteria. Survival data [overall survival (OS)] meant the time from the date of diagnosis until the date of death from any reason, or the point of the last follow-up.

\section{Statistical analysis}

Multi-class variables such as race, age, or tumor size were contrasted by chi-square tests between ELCNC, ESCNC, and ESCC, while two categorical variables or ordered variables like sex, tumor grade, or stage were compared through rank sum tests. Log-rank tests and Kaplan-Meier analyses were applied for univariate analyses, aiming to construct survival curves. Furthermore, Cox model tests were used for multivariate analyses to further predict the progress of ELCNC. All the analyses were conducted by using SPSS (version 25) software (SPSS, Chicago, IL, USA), and $\mathrm{P}<0.05$ was regarded as statistically significant. All were two-sided tests. Survival curves were generated using $\mathrm{R}$ language (v3.5.1) software, and the primary packages were Survival and Survminer $(8,9)$.

\section{Results}

\section{Comparisons of clinicopathological characteristics between ELCNC, ESCNC, and ESCC}

In total, 36 patients with ELCNC, 218 patients with ESCNC, and 7,901 patients with ESCC were enrolled between 2004 and 2015 after careful screening. As shown in Table 1, 31 males and 5 females were included among the ELCNC group, with the majority ranging in age 60-80 years and a median age of 66.75 years. Thirty-three (91.7\%) of the patients were Caucasian. Most ELCNC patients (58.4\%) were AJCC stage IV, $8.3 \%$ were stage I, $13.9 \%$ were stage II, and $8.3 \%$ were stage III. Patients diagnosed as ELCNC were statistically less commonly female patients $(\mathrm{P}=0.007)$, had larger tumor sizes $(\mathrm{P}=0.010)$, had more poorly or undifferentiated grades $(\mathrm{P}=0.030)$, and more $\mathrm{N}+$ disease $(\mathrm{P}<0.001)$ than those of ESCNC patients. Nevertheless, the risk factors of race $(\mathrm{P}=0.004)$, sex $(\mathrm{P}=0.009)$, having insurance $(\mathrm{P}<0.001)$, marital status $(\mathrm{P}=0.026)$, tumor size $(\mathrm{P}=0.003)$, tumor grade $(\mathrm{P}<0.001)$, AJCC $7^{\text {th }}$ stage $(\mathrm{P}<0.001)$, surgery $(\mathrm{P}<0.001)$, and radiotherapy $(\mathrm{P}<0.001)$ indicated significant differences between ELCNC versus ESCC.

\section{Analyses of ELCNC prognostic factors}

Survival data indicated that the 1- and 3-year survival rates of ELCNC were $27.8 \%$ and $8.3 \%$, respectively. No patients survived for more than 5 years. There were significant differences in the progresses between ELCNC, ESCNC and ESCC using a calibration curve $(\mathrm{P}=0.00042)$ especially for ELCNC and ESCC $(\mathrm{P}=0.0058)$ (Figure 1 and Figure $S 1 A$ ). Nevertheless, as suggested by the data shown in Figure $S 1 B$, the survival times of ELCNC and ESCNC were similar $(\mathrm{P}=0.2)$.

Specific prognostic factors in patients with ELCNC were investigated by univariate analyses. As shown in Figure 2, age $(\mathrm{P}=0.015)$, AJCC $7^{\text {th }}$ stage $(\mathrm{P}=0.039)$, and $\mathrm{M}$ stage $(\mathrm{P}=0.02)$ with prognoses of ELCNC were proven to be significantly different. Older age and higher AJCC $7^{\text {th }}$ stage were correlated with shorter survival time. 
Table 1 Comparison of the clinicopathological characteristics between esophageal large cell neuroendocrine carcinoma (ELCNC) esophageal small cell neuroendocrine carcinoma (ESCNC), and esophageal squamous cell carcinoma (ESCC)

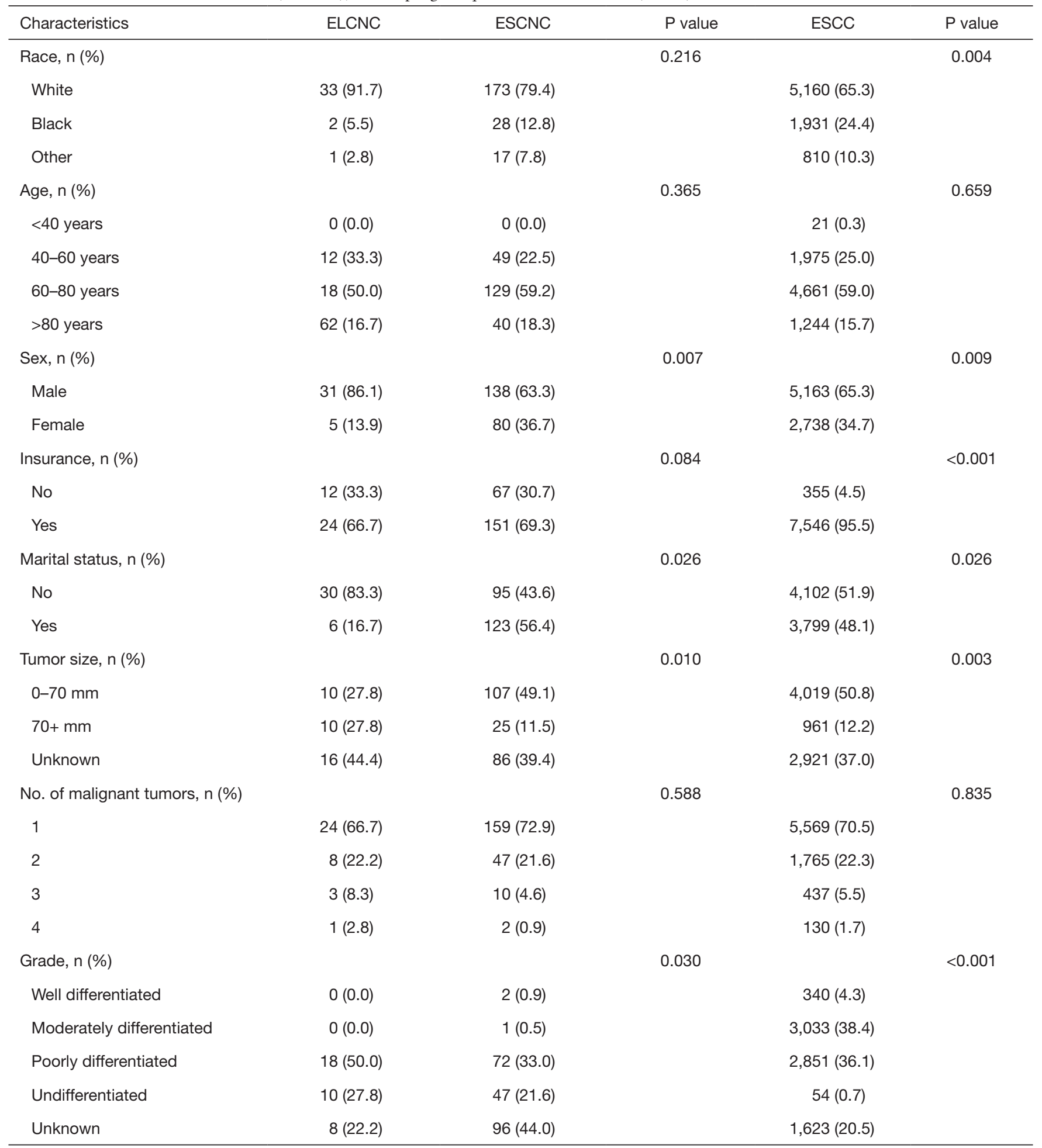

Table 1 (continued) 
Table 1 (continued)

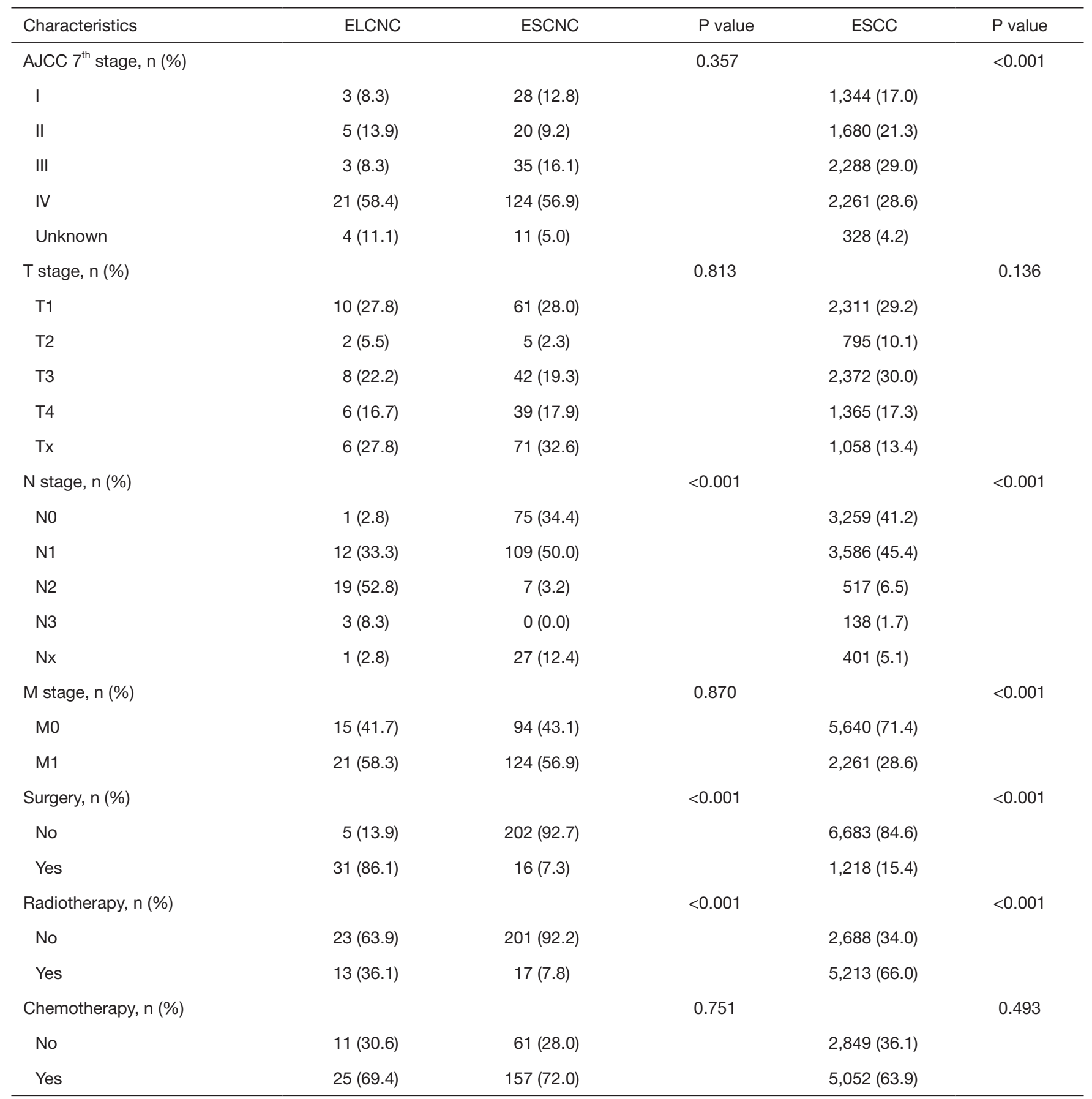

ELCNC, esophageal large cell neuroendocrine carcinoma; ESCNC, esophageal small cell neuroendocrine carcinoma; ESCC, esophageal squamous cell carcinoma. 


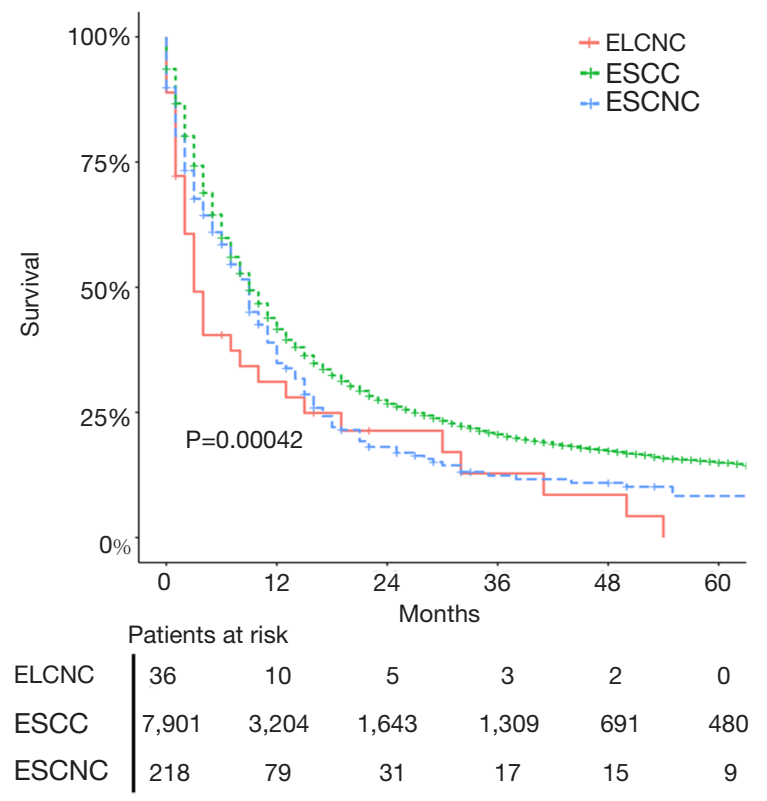

Figure 1 The survival curve between esophageal large cell neuroendocrine carcinoma (ELCNC), esophageal squamous cell carcinoma (ESCC) and esophageal small cell neuroendocrine carcinoma (ESCNC).

Nevertheless, total univariate analyses did not show that patients who accepted any therapy had a better prognosis than patients who did not.

As shown in Table 2, a more detailed analysis indicated that the risk factors of age $(\mathrm{P}=0.001)$ and $M$ stage $(\mathrm{P}=0.004)$ were significantly different as assessed by univariate analyses, which were confirmed to be independent factors in accordance with multivariate analyses. Therefore, olderaged patients and higher $M$ stages may lead to the worse prognoses, according to multivariate analyses data.

\section{Discussion}

Few cases of ELCNC have been reported in the literature. This may be a result of the poorly developed neuroendocrine system in the esophagus $(10,11)$. Currently, ELCNC is diagnosed according to the presence of neuroendocrine (NE) morphology, especially when more than $20 \%$ of tumor cells express NE markers (7).

Due to the poor prognosis of ELCNC, the general survival time is no more than 5 years. Similar to previous studies $(12,13)$, we indicated that the prognosis of ELCNC was worse than for ESCC $(\mathrm{P}=0.0058)$, with no significant difference of ESCNC $(\mathrm{P}=0.2)$. It is worth mentioning that
ELCNC and ESCNC, forming part of the spectrum of neuroendocrine tumors, show later tumor differentiation and TNM stage relatively. Therefore, the prognosis is worse than squamous cell carcinoma.

We found from the SEER database that there were significant differences between ELCNC, ESCNC, and ESCC in terms of sex, marital status, tumor size, tumor grade, $\mathrm{N}$ stage, surgery, and radiotherapy. In addition to this, the risk factors of race, insurance, total TNM stage, and M stage differed between ELCNC and ESCC. Clinically, ELCNC and ESCNC could be distinguished by immunohistochemistry, so it is not difficult to observe similarities and differences in biological characteristics between them (14). However, considering the content of neuroendocrine cells in tumor tissues and the rare number of cases, several clinicopathological features such as tumor size and grade of the two esophageal neuroendocrine tumors could be used in our study. Furthermore, we also detected that age, TNM stage, and $M$ stage were independent influencing factors for the prognosis of patients with ELCNC, using univariate analyses. Thus, only age and M stage remained after multivariate analyses. All the patients from our study were middle-aged and older ( $>40$ years old), and the average age of onset was approximately 65 years of age, which was consistent with previous literature $(11,15)$. Because mucosal glands of the distal esophagus typically contain more neuroendocrine cells, as shown by endoscopic findings, ELCNCs are mainly located in the lower third of the esophagus $(11,16)$. Our research also suggested that most cases were in the advanced stage, in agreement with the four phases of TNM staging. Consequently, the possibility of distant metastasis was greater.

At present, due to the low incidence of ELCNC, prospective and randomized clinical trials of optimal treatments are not easily accomplished. Given the similarities of histological and clinical features between ELCNC and ESCNC, studies have shown that multimodal therapies should be used in ELCNC, which normally is the same regimen used for SCLC $(17,18)$. To some extent, radical surgery is still considered an important part of the comprehensive treatment regimen for the limited period of ELCNC. Medgyesy et al. demonstrated that the survival time of the radiotherapy and chemotherapy group was also lower than that of the surgery group (10). However, as a systemic disease, most patients with ELCNC have distant micrometastases and regional lymph node metastasis at the time of surgery. Therefore, surgery alone may not completely eradicate the tumor. Raja $e t$ al. conducted a large sample 

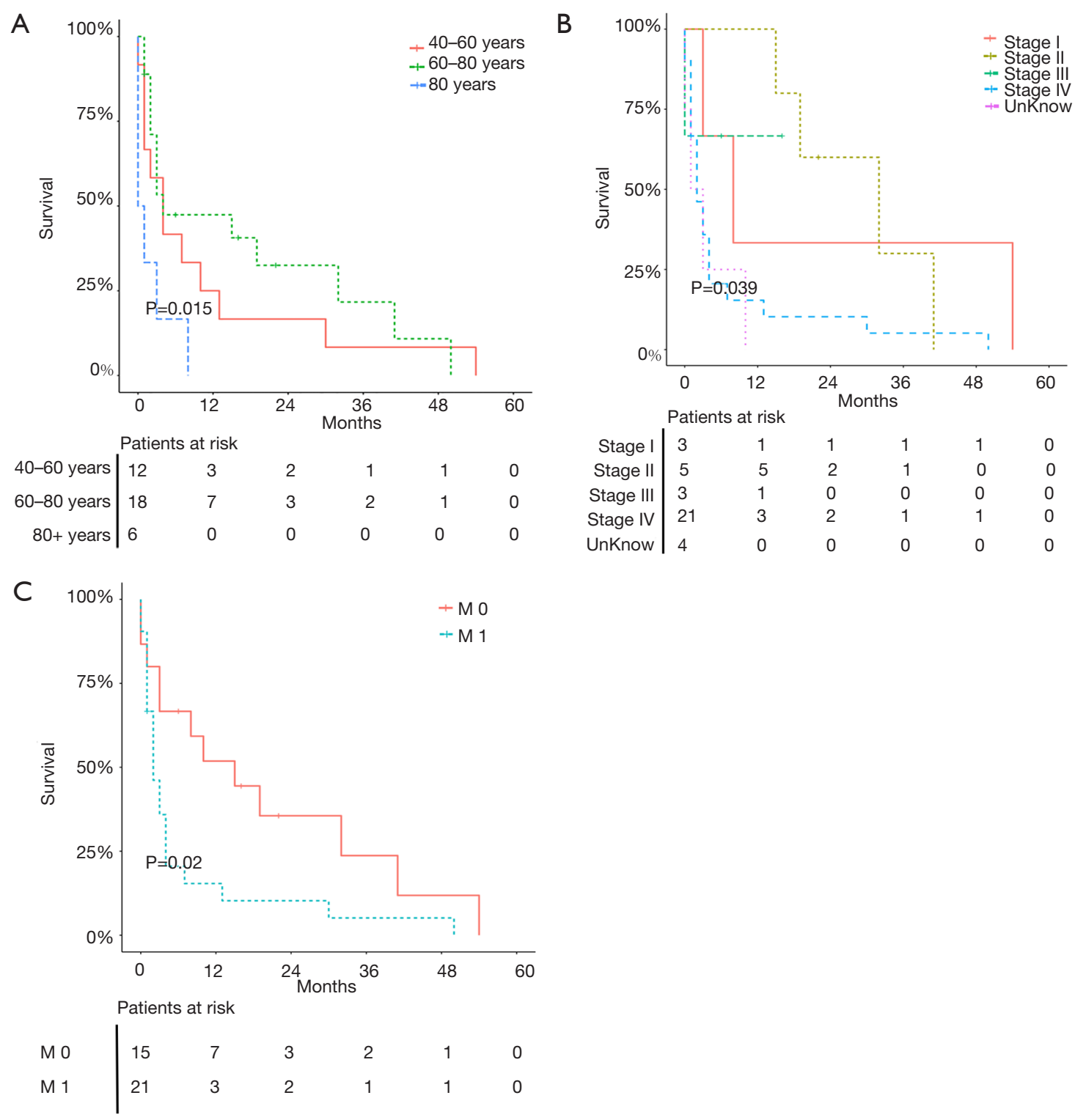

Figure 2 Kaplan-Meier estimate of overall survival in patients treated by (A) age, (B) AJCC TMN stage (C) AJCC M stage.

meta-analysis and concluded that chemotherapy should be the most basic treatment, and chemotherapy combined with surgery or chemotherapy combined with radiotherapy might bring further survival benefits (19). However, resulted from the small sample size, there was no significant difference in the prognosis of all therapeutic treatments in our study.

Some reports on targeted therapies (such as bevacizumab, nimotuzumab, and thalidomide) have been applied in SCLC patients, but they have not brought a clear benefit. The effect of targeted therapy in ELCNC is rarely reported and requires further study; however, this could be a treatment option for $\operatorname{ELCNC}(20,21)$.

\section{Conclusions}

Our study showed esophageal large cell neuroendocrine carcinoma as having independent clinicopathological features that were different from esophageal small cell carcinoma and esophageal squamous cell carcinoma. We further demonstrated the main related risk factors for the prognosis of ELCNC, and survival curves predicting longterm progress were further analyzed. 
Table 2 Univariate and multivariate Cox proportional hazards analysis

\begin{tabular}{|c|c|c|c|c|}
\hline Patient characteristics & \multicolumn{2}{|c|}{ Univariate analysis } & \multicolumn{2}{|c|}{ Multivariate analysis } \\
\hline Race & & 0.117 & - & - \\
\hline White & Reference & & - & - \\
\hline Black & $3.889(0.825-18.332)$ & 0.086 & - & - \\
\hline $40-60$ years & Reference & & Reference & \\
\hline $60-80$ years & $0.736(0.332-1.631)$ & 0.450 & $0.694(0.296-1.626)$ & 0.400 \\
\hline $80+$ years & $2.762(0.980-7.787)$ & 0.055 & $8.140(2.344-28.268)$ & 0.001 \\
\hline Insurance & & 0.566 & - & - \\
\hline No & Reference & & - & - \\
\hline Yes & $1.311(0.497-3.464)$ & & - & - \\
\hline Marital status & & 0.549 & - & - \\
\hline No & Reference & & - & - \\
\hline Yes & $0.806(0.384-1.692)$ & & & \\
\hline Tumor size & & 0.719 & - & - \\
\hline $0-70 \mathrm{~mm}$ & Reference & & - & - \\
\hline 3 & 4.054 (1.105-14.881) & 0.983 & - & - \\
\hline 4 & $<0.001$ & $<0.001$ & - & - \\
\hline Grade & & 0.375 & - & - \\
\hline Poorly differentiated & Reference & 0.993 & - & - \\
\hline Undifferentiated & $1.582(0.677-3.697)$ & 0.290 & - & - \\
\hline Unknown & $1.669(0.666-4.185)$ & 0.275 & - & - \\
\hline AJCC $7^{\text {th }}$ stage & & 0.039 & & 0.752 \\
\hline I & Reference & & Reference & \\
\hline II & $1.008(0.180-5.659)$ & 0.993 & $0.681(0.033-14.017)$ & 0.803 \\
\hline III & $1.048(0.092-11.946)$ & 0.970 & $0.492(0.016-15.318)$ & 0.686 \\
\hline IV & 3.402 (0.776-14.920) & 0.105 & $2.279(0.127-41.042)$ & 0.576 \\
\hline Unknown & $4.695(0.815-27.038)$ & 0.083 & $0.992(0.085-11.523)$ & 0.995 \\
\hline
\end{tabular}

Table 2 (continued) 
Table 2 (continued)

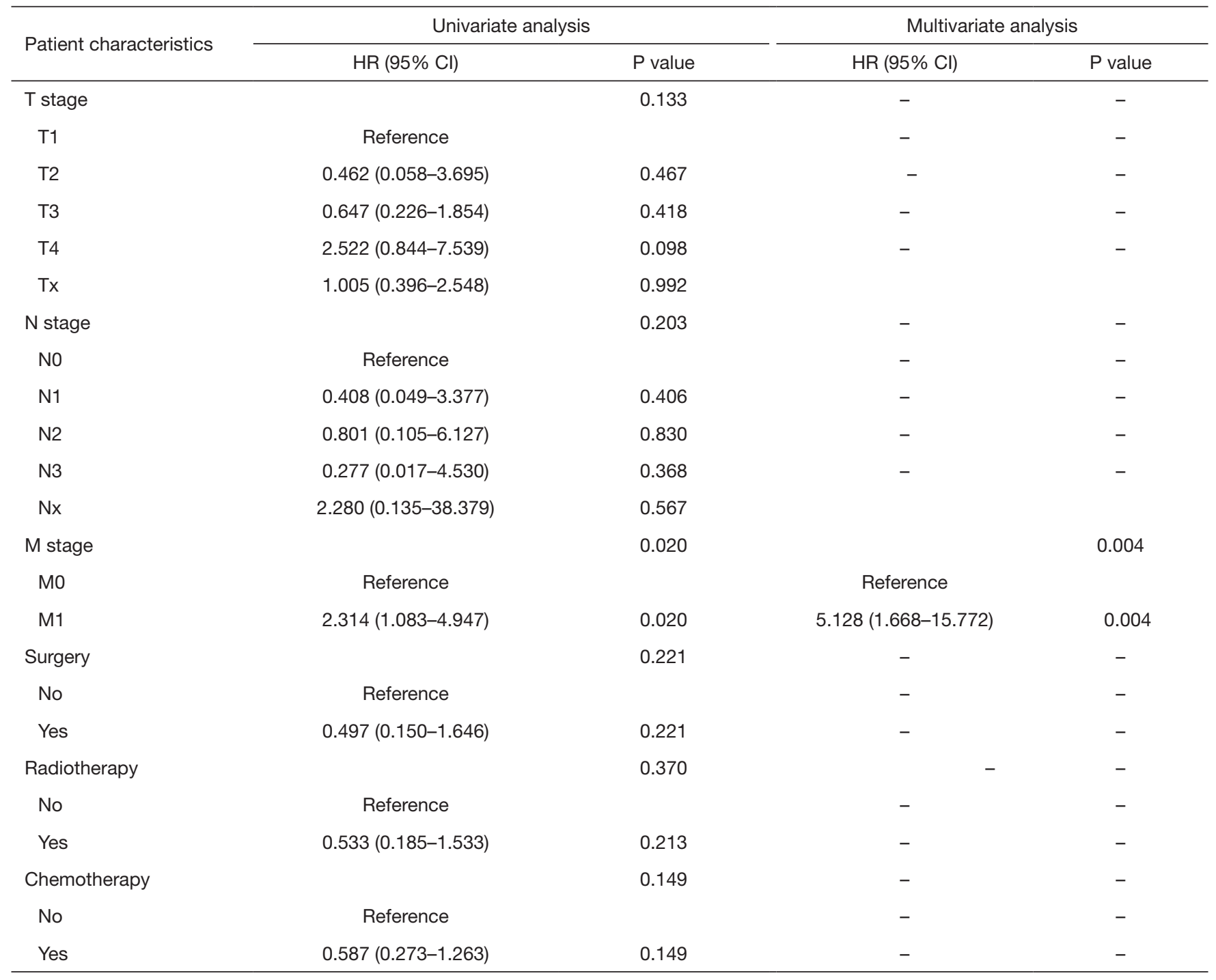

\section{Acknowledgments}

Funding: This work was supported by the Suzhou Industry Technology Innovation Program (SYSD2017172) (www.szkj.gov.cn), Research Program of Shanghai Health and Family Planning Commission (201640102) (www.wsjsw. gov.cn).

\section{Footnote}

Conflicts of Interest: The authors have no conflicts of interest to declare.

Ethical Statement: The authors are accountable for all aspects of the work in ensuring that questions related to the accuracy or integrity of any part of the work are appropriately investigated and resolved. All the data files were obtained with permission from the SEER database, which is publicly available, therefore approval was not necessary by the local ethics committee.

\section{References}

1. Bray F, Ferlay J, Ferlay J, et al. Global cancer statistics 2018: GLOBOCAN estimates of incidence and mortality worldwide for 36 cancers in 185 countries. CA Cancer J Clin 2018;68:394-424. 
2. Huang FL, Yu S. Esophageal cancer: Risk factors, genetic association, and treatment. Asian J Surg 2018;41:210-15.

3. Qin Y, Guo C, Chang X, et al. Characteristics and treatment of patients with neuroendocrine carcinoma of the gastroesophageal junction: an analysis of 13 cases. Transl Cancer Res 2017;6:1340-4.

4. Flejou J. WHO Classification of digestive tumors: the fourth edition. Ann Pathol 2011;31:S27-31.

5. Shia J, Tang L, Weiser M, et al. Is non-small cell type high-grade neuroendocrine carcinoma of the tubular gastrointestinal tract a distinct disease entity? Am J Surg Pathol 2008;32:719-31.

6. McKeown F. Oat-cell carcinoma of the oesophagus. J Pathol Bacteriol 1952;64:889-91.

7. Jiang SX, Mikami T, Umezawa A, et al. Gastric large cell neuroendocrine carcinomas: a distinct clinicopathologic entity. Am J Surg Pathol 2006;30:945-53.

8. Custodio A, Carmona-Bayonas A, Jiménez-Fonseca P, et al. Nomogram-based prediction of survival in patients with advanced oesophagogastric adenocarcinoma receiving first-line chemotherapy: a multicenter prospective study in the era of trastuzumab. Br J Cancer 2017;116:1526-35.

9. Suzuki A, Xiao L, Hayashi Y, et al. Nomograms for prognostication of outcome in patients with esophageal and gastroesophageal carcinoma undergoing definitive chemoradiotherapy. Oncology 2012;82:108-13.

10. Medgyesy CD, Wolff R, Putnam J, et al. Small cell carcinoma of the esophagus: the University of Texas M. D. Anderson Cancer Center experience and literature review. Cancer 2000;88:262-7.

11. Huang Q, Wu H, Nie L, et al. Primary high-grade neuroendocrine carcinoma of the esophagus: a clinicopathologic and immunohistochemical study of 42 resection cases. Am J Surg Pathol 2013;37:467-83.

Cite this article as: Yuan G, Zhan C, Zhu D, Xie H, Wei T, Lu T, Yang Y, Zhu Y, Wang Q. Population-based analysis of esophageal large cell neuroendocrine carcinoma between 2004 and 2015. J Thorac Dis 2019;11(12):5480-5488. doi: 10.21037/ jtd.2019.11.34
12. Tomiyama T, Orino M, Nakamaru K, et al. Esophageal Large-Cell Neuroendocrine Carcinoma with Inconsistent Response to Treatment in the Primary and Metastatic Lesions. Case Rep Gastroenterol 2018;12:234-9.

13. Kuriry H, Swied A. Large-Cell Neuroendocrine Carcinoma of the Esophagus: A Case from Saudi Arabia. Case Rep Gastroenterol 2015;9:327-34.

14. Maru DM, Khurana H, Rashid A, et al. Retrospective study of clinicopathologic features and prognosis of highgrade neuroendocrine carcinoma of the esophagus. Am J Surg Pathol 2008;32:1404-11.

15. Lu XJ, Luo J, Ling Y, et al. Management of small cell carcinoma of esophagus in China. J Gastrointest Surg 2013;17:1181-7.

16. Bennouna J, Bardet E, Deguiral P, et al. Small cell carcinoma of the esophagus: analysis of 10 cases and review of the published data. Am J Clin Oncol 2000;23:455-9.

17. Gollard R, Ellis C, VanderHarten C. Small cell/ neuroendocrine tumors of the esophagus: presentation of two cases and review of the literature. Tumori 2010;96:780-3.

18. Sun KL, He J, Cheng G, et al. Management of primary small cell carcinoma of the esophagus. Chin Med J (Engl) 2007;120:355-8.

19. Raja S, Rice TW, Rajeswaran J, et al. Esophageal smallcell cancer: study of a rare disease. Dis Esophagus 2013;26:690-5.

20. Ma Z, Cai H, Cui Y. Progress in the treatment of esophageal neuroendocrine carcinoma. Tumour Biol 2017;39:1010428317711313.

21. Ito T, Lee L, Jensen RT. Treatment of symptomatic neuroendocrine tumor syndromes: recent advances and controversies. Expert Opin Pharmacother 2016;17:2191-205. 
A

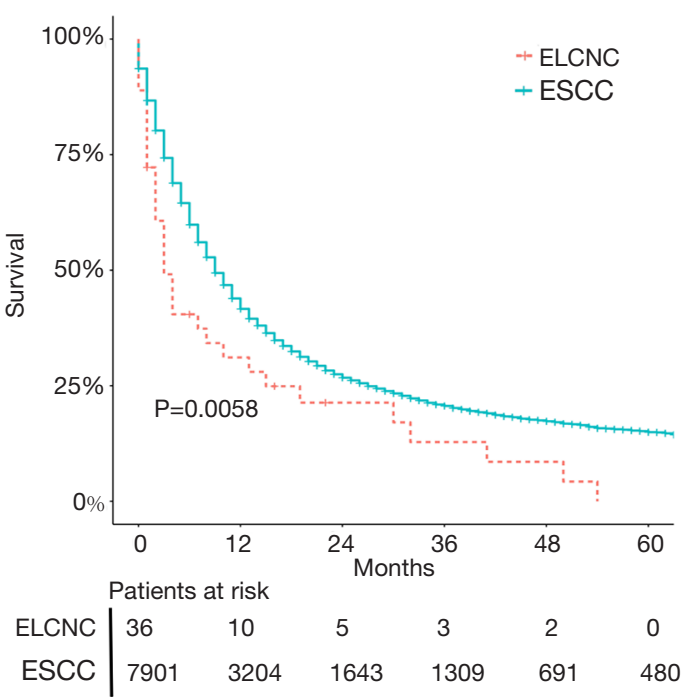

B

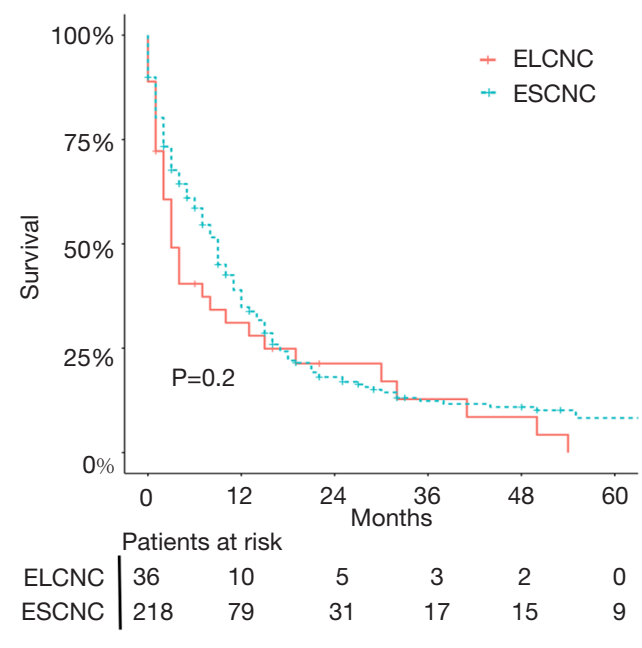

Figure S1 Comparison of the survival curves of different types of esophageal cancer. (A) The survival curve between esophageal large cell neuroendocrine carcinoma (ELCNC) and esophageal squamous cell carcinoma (ESCC); (B) the survival curve of esophageal large cell neuroendocrine carcinoma (ELCNC) and esophageal small cell neuroendocrine carcinoma (ESCNC). 